\title{
Machining Deformation Analysis of Aircraft Monolithic Components Based on the Energy Method
}

Xiaoming Huang ( $\sim$ hxm2552@163.com )

Binzhou University

Xiaoliang Liu

Binzhou University

Weitao Sun

Binzhou University

Jiaxing Li

Binzhou University

Yongbin Chen

Binzhou University

Dechen Wei

Binzhou University

Guichu Ding

Tianjin Vocational and Technical Normal University: Tianjin University of Technology and Education

\section{Original Article}

Keywords: Machining deformation, Residual stresses, Energy method, Equivalent bending stiffness, Aircraft monolithic component

Posted Date: February 11th, 2021

DOI: https://doi.org/10.21203/rs.3.rs-182793/v1

License: (c) (i) This work is licensed under a Creative Commons Attribution 4.0 International License. Read Full License 


\section{Title page}

\section{Machining Deformation Analysis of Aircraft Monolithic Components Based on the Energy Method}

Xiao-Ming Huang, born in 1981, is currently an associate professor at Mechatronics Engineering Department, Binzhou University, China. He received his $\mathrm{PhD}$ degree from Shandong University, China, in 2015. His research interests is machining of aircraft monolithic components.

Tel: +86-18306490081; E-mail: hxm2552@163.com

Xiao-Liang Liu, born in 1981, is currently an associate professor at Mechatronics Engineering Department, Binzhou University, China. He received his $\mathrm{PhD}$ degree from State Key Laboratory of Mechanics and Control of Mechanical Structures, Nanjing University of Aeronautics and Astronautics, China, in 2019.

E-mail: jasonxlliu@163.com

Wei-Tao Sun, born in 1986, is currently a lecturer at Mechatronics Engineering Department, Binzhou University, China. He received his $\mathrm{PhD}$ degree on mechanical engineering, Dalian University of Technology, China, in 2019.

E-mail: sun_wei_tao@163.com

Jia-Xing Li, born in 1990, is currently a lecturer at Mechatronics Engineering Department, Binzhou University, China. He received his master degree on aviation engineering in Civil Aviation University of China, China, in 2016.

E-mail: 981764286@qq.com

Yong-Bin Chen, born in 1984, is currently an associate professor at Mechatronics Engineering Department, Binzhou University, China. He received his PhD degree from College of Aerospace Engineering, Nanjing University of Aeronautics and Astronautics, China, in 2018. His research interests include aircraft design, aircraft manufacturing engineering.

E-mail: chenyongbinfly@126.com

De-Chen Wei, born in 1985, is currently an associate professor at Mechatronics Engineering Department, Binzhou University, China. He received his PhD degree from College of Aerospace Engineering, Nanjing University of Aeronautics and Astronautics, China, in 2017. His research interests include non-traditional machining, aircraft manufacturing engineering.

E-mail: $372571316 @ q q . c o m$

De-Chen Wei, born in 1994, is currently a master candidate at Mechanical Engineering Department, Tianjin Vocational Technology Normal University, China. His research interests is prediction and control of machining deformation on aircraft monolithic components.

E-mail: $372571316 @ q q . c o m$

\section{Corresponding author: Xiao-Ming Huang E-mail: hxm2552@163.com}




\title{
Machining Deformation Analysis of Aircraft Monolithic Components Based on the Energy Method
}

\author{
Xiao-Ming Huang ${ }^{1,3} \cdot X_{1}$ iao-Liang Liu ${ }^{1} \cdot$ Wei-Tao Sun $^{1,3} \cdot$ Jia-Xing Li $^{1,3} \cdot$ Yong-Bin Chen ${ }^{1} \cdot$ De-Chen Wei $^{1} \cdot$ Gui-Chu \\ Ding $^{2}$
}

Received xx, 202x; revised xx, 202x; accepted xx, 202x

(C) Chinese Mechanical Engineering Society and Springer-Verlag Berlin Heidelberg 2017

\begin{abstract}
In the process of machining aircraft monolithic components, the initial stress in the blank will cause machining deformation. Based on the energy method, an analytical mathematical model of machining deformation is presented in this paper. The key point is to transform the energy in the removed material into the deformation energy of the part after machining. The initial residual stress of 7050-T7451 aluminum alloy blank and single frame part are used as investigated case in the analytical model. For layer by layer machining, the deformation evolution is closely related to the tensile or compressive properties of the initial stress of removed material. Combined with the change of neutral axis position, The machining deformation is calculated by theoretical model. Then, FEM simulation is carried out to analyze the influence of stiffening ribs on machining deformation utilizing the semi-analytical model of equivalent bending stiffness. Furthermore, experiments are set up to verify the validity of the theory and FEM data. The results indicate that the deformation results of the experiment are consistent with that of theory and FEM model. Deformation is determined by energy of removed material. This paper provides a novel theoretical approaches for the further investigation of this issue.
\end{abstract}

Keywords: Machining deformation • Residual stresses • Energy method - Equivalent bending stiffness - Aircraft monolithic component

Xiao-Ming Huang

hxm2552@163.com

1 Mechatronics Engineering Department, Binzhou University, Binzhou 256603, China

2 Mechanical Engineering Department, Tianjin Vocational Technology Normal University, Tianjin 300222, China

3 Institute of aircraft manufacturing technology, Binzhou University, Binzhou 256603, China

\section{Introduction}

With the rapid development of modern aviation industry, more and more aircraft monolithic components are applied in the big aircraft and fighter such as wing, girder and bulkhead in fuselage [1-2]. They have the advantage of lightening the weight of the airplane. Characteristics of aircraft monolithic components are large size, complex structure, and low stiffness because of the material removal rate of more than $93 \%$. After machining, they deformed easily. Machining deformation of aircraft monolithic components resulted by the combined action of many factors, including blank residual stress, machining residual stress, components geometry clamping conditions, et al [3-5].

Aluminum alloy is one of the most commonly used materials for aircraft monolithic components. For aviation aluminum alloy material, initial residual stress is formed after the process of the casting, hot rolling, quenching, pre-stretching, and aging. Previous research had shown that the proportion of the machining deformation caused by the initial residual stress is about $90 \%$ [6-7]. Zhang et al.'s research shown that aircraft monolithic components deformation were mainly affected by the removed material, and making the stress in blank symmetrically distributed was one of the ways to minimize the machining deformation [8]. Ye et al. [9] revealed the relationship between machining positions of initial residual stress in blank and components deformations. The authors machined C919 straight beam with step decrease iterative algorithm for minimizing the machining deformation. The results indicated that the optimization of machining position can 
decrease deformation about $99.79 \%$ with step decrease iterative algorithm for the beam.

Machining sequence is another main factor that influences the initial residual stress redistribution during the machining process. Cerutti et al. [10] studied the influence of the material removal sequence on the residual stress release in the machining deformation of aircraft monolithic components. The optimized machining sequence obtained a maximum deformation of $0.04 \mathrm{~mm}$ compared with $0.5 \mathrm{~mm}$ of conventional machining process case. Ding et al. [11] studied the machining sequence considering the initial residual stresses and component geometry. Six machining sequences were investigated in their paper. Hao et al. [12] proposed a dynamic machining process planning based on deformation monitoring data. Monitoring points were employed to optimize the machining sequence which was adaptively adjusted in each machining layer. Mikel et al. [13] proposed a novel methodology for the machining operation with optimized machining sequence. Aerospace turbine component deformation was reduced $72.6 \%$ by using the rebalanced machining sequence.

In addition to the using of the redistribution of initial residual stress, the introduction of additional favorable stress is helpful to minimize the machining deformation. $\mathrm{Lu}$ et al. [14-15] invested the relationship between the position of introduced rolling residual stress and the reduction of machining deformation. The deformation correction key position of aviation beam was determined. The research results show that the maximum deformation decreases from $0.333 \mathrm{~mm}$ to $0.06 \mathrm{~mm}$, and the deformation elimination rate reaches $82.0 \%$. Yao et al. [16] applied the milling residual stress and shot peening residual stress to reduce machining deformation of large aeronautical blade. The maximum uneven residual stress reached $840 \mathrm{MPa}$ at the depth of 30 $\mu \mathrm{m}$.

Geometry characteristics of aircraft monolithic components are also closely related to machining deformation. Denkena's research demonstrated that the machining deformation with different structures get varying bending law in the same machining conditions. The researchers argue that the components structures offer boundary constraints to the distribution of residual stresses. The machining deformation of single frame component was twice as much as that of a double sided frame component in experiments [17-18].

Stiffness of monolithic components is varied with the machining. $\mathrm{Li}$ et al. [19] investigated the machining deformation of aircraft monolithic components by use of the equivalent bending stiffness model. The finite element methodand experiment results indicated that the machining deformation was sensitive to the stiffness of the component in the lengthwise direction, and it was not significantly influenced by the stiffness in width. Huang et al. [20-21] taken a long beam of a civilian airplane as the research case, and found the stiffness reduction ratio was $68.5 \%$ when the component was finished. The machining deformation was forecasted in utilizing of stiffness evolution and residual stress redistribution in their research. Sun [22] used the analytic approach to determine the stiffness weakest position of the parts. Minimized machining deformation was obtained by the harmonic response analysis method.

There are many factors that cause the deformation of aircraft monolithic components. The initial residual stress is the main factor of causing machining deformation. In this paper, we present a view that the conversion of energy also can clarify this issue. It is different from the above methods based on redistribution of initial residual stress. Initial residual stress of the blanks is converted into external load when the materials are removed, which leads to the deformation of the aircraft monolithic components after machining. To our knowledge, the relationship between energy and machining deformation has not been reported.

In this paper, the modeling process for machining deformation in the machining process is presented based on the energy method. A single frame part is taken as research project to establish the machining deformation prediction model in Section 2. The deformation of aircraft monolithic components is calculated using FEM in Section 3. The equivalent stiffness model is used in the FEM calculation process. The results are discussed combining with theory results. The theoretical model results are verified and compared with experiment results and FEM results in Section 4.

\section{Mechanism of Machining Deformation Based on Energy Theory}

For aviation aluminum alloy blank, the initial residual stress holds the following equation because they are in equilibrium within the whole blank before the aircraft monolithic component is machined.

$$
\left\{\begin{array}{l}
\int_{\Omega} \sigma_{x}(z) \cdot d y d z=0 \\
\int_{\Omega} \sigma_{x}(z) \cdot z \cdot d y d z=0 \\
\int_{\Omega} \sigma_{y}(z) \cdot d x d z=0 \\
\int_{\Omega} \sigma_{y}(z) \cdot z \cdot d y d z=0
\end{array}\right.
$$


where $\sigma_{x}(z)$ is the initial stress in rolling direction distributed along the thickness direction, $\sigma_{y}(z)$ is the initial stress in transverse direction distributed along the thickness direction. $x, y, z$ are the direction of rolling, transverse and thickness respectively. $\Omega$ is the region of aviation aluminum alloy blank. When aircraft monolithic component is machined, initial residual stresses release gradually with the removal of the material. Equivalent loads in the rolling direction and the transverse direction can be obtained as [21]:

$$
\left\{\begin{array}{l}
F_{x}=\int_{M} \sigma_{x}(z) \cdot d y d z \\
F_{y}=\int_{M} \sigma_{y}(z) \cdot d x d z \\
M_{x}=\int_{M} \sigma_{x}(z) \cdot z \cdot d x d z \\
M_{y}=\int_{M} \sigma_{y}(z) \cdot z \cdot d x d z
\end{array}\right.
$$

where $M$ is the region of the removed material.

When aircraft monolithic component is machined, the residual stress redistributes. Usually, two dimensional (2D) model was used to analyze the mechanism of machining deformation caused by that. According to the 2D model, the initial residual stress torque and additional torque in the machining process can be obtained [25]. However, this analysis is only applicable to the $2 \mathrm{D}$ model and provide guidance for the follow-up research. It is not suitable for the actual 3D model of aircraft monolithic component.

In this paper, it is assumed that the deformation energy of the components $E_{d}$ equates to the energy $V_{\varepsilon}$ stored in the removed material. When the cutting layer material is removed, aircraft monolithic components will deform based on energy conservation relationship [23-24].

$$
\left\{\begin{array}{l}
E_{d}=V_{\varepsilon} \\
V_{\varepsilon}=\frac{1}{2} \int_{\Omega} \sigma(z) \cdot \varepsilon \cdot d x d y d z
\end{array}\right.
$$

Figure 1 is an aircraft monolithic components made of 7050-T7451 aluminum alloy. To simplify the calculation, a single frame part is selected as the analytical model. The length, width and height of the single frame structure are set as $156 \mathrm{~mm}, 50 \mathrm{~mm}$ and $30 \mathrm{~mm}$ respectively, as showed in Figure 1. The thickness of the side wall and the bottom wall is $3 \mathrm{~mm}$.

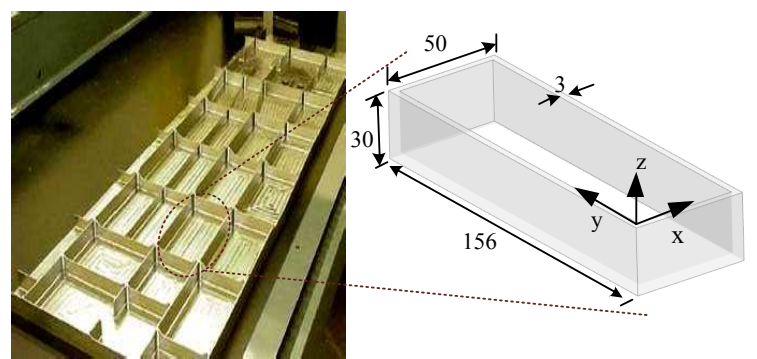

Figure 1 Aircraft monolithic component and single frame part

The initial residual stress distribution of 7050-T7451 aluminum alloy blank was measured by crack compliance method, as shown in Figure 2 [26]. The single frame part is located in the region of $0-30 \mathrm{~mm}$ in the blank. The machining process is cutting the material layer by layer, i.e. removing, (1), (2)... layers materials in turn. Initial residual stress curve of rolling direction is given by the Gaussian fitting, which is expressed as follows [27]:

$\sigma_{x}=70.74-71.51 e^{-0.00393 Z^{2}}-\sum_{i=1}^{2} 90.63 e^{-0.017\left[Z-23.18 \times(-1)^{i}\right]^{2}}$
$\sigma_{y}=2.76-\sum_{i=1}^{2} 17.02 e^{-0.0487\left[Z-26.34 \times(-1)^{i}\right]^{2}}+\sum_{i=1}^{2} 4.944 e^{-0.0367\left[Z-12.01 \times(-1)^{i}\right]^{2}}$

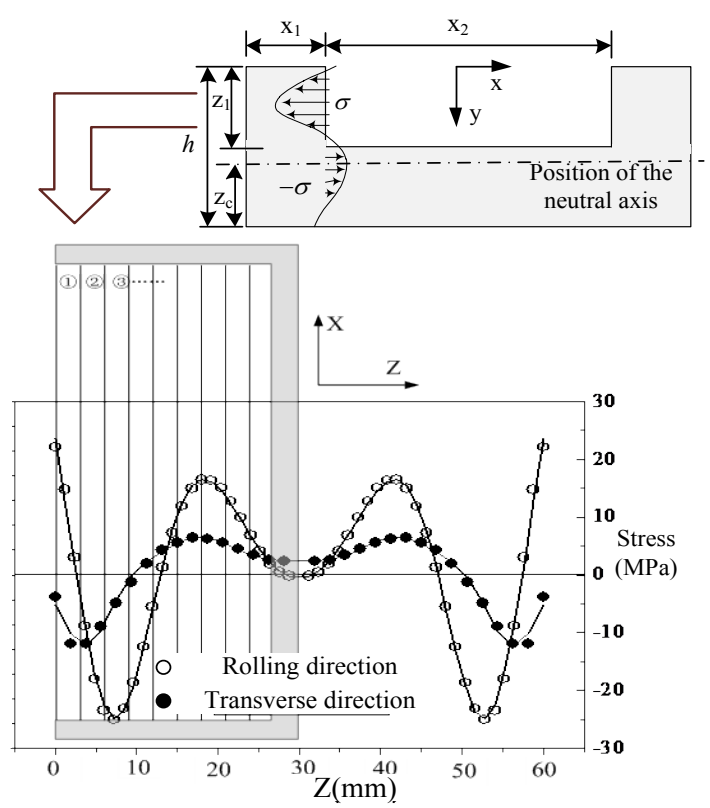

Figure 2 Initial residual stress of aluminum alloy blank

According to Hooke's law, the stress/strain energy can be expressed as the following formula (5) when the removed material thickness is $z$. 


$$
\left|V_{\varepsilon}\right|=\int_{0}^{z} \frac{\sigma^{2} x y}{2 E} d z
$$

Firstly, the absolute value of $V_{\varepsilon}$ is calculated based on initial residual stress and removed material. Then, the deformation energy is determined to be positive or negative according to the compressive stress or tensile stress. This is because that the deformation energy applied to components will lead to deformation in the opposite direction for compressive stress and tensile stress.

Figure 3 is the flow chart of component deformation analysis. The position of the neutral axis moves down gradually during the machining process layer by layer as show in Figure 2. When the stress of the removed material is tensile, and the region of the removed material layer is above the neutral axis, the component will bend upward. Instead, the component will bend downward if one of the factors is conversed.

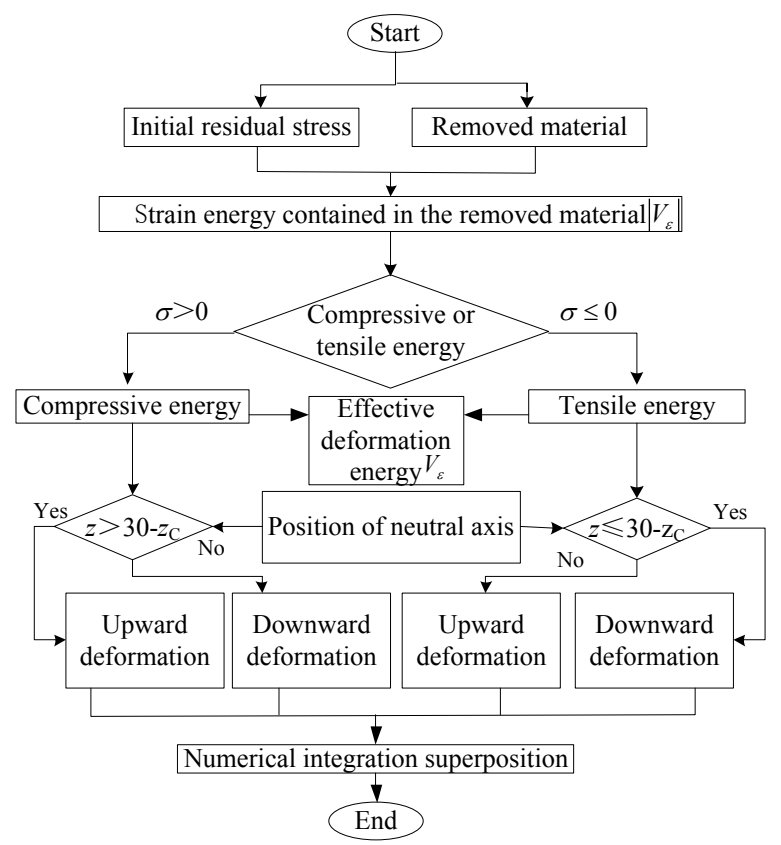

Figure 3 Flow chart of component deformation analysis

The cross section of the single spacer is U-shaped, as shown in Figure 2. The centroid position of the U-shaped section is the neutral axis position for the single frame component. The centroid position $z_{c}$ calculation formula is as following:

$$
z_{c}=\frac{\int z d A}{A}=\frac{\int_{0}^{h-z_{1}} z\left(2 x_{1}+x_{2}\right) d z+\int_{h-z_{1}}^{h} z\left(2 x_{1}\right) d z}{\left(2 x_{1}+x_{2}\right)\left(h-z_{1}\right)+2 x_{1} z_{1}}
$$

where $A$ is the cross-sectional area, $x_{1}$ is the wall thickness of the thin-wall parts, $x_{2}$ is the width of the removed material layer, $z_{1}$ is the depth of the removed material layer, and the distance between the neutral axis of the U-shaped section and bottom wall is neutral axis position $z_{\mathrm{c}}$.

Utilizing the formula (6), the position change curve of the neutral axis in the machining process is obtained, as show in Figure 4. It can be seen that in the initial stage, the neutral axis position linear decreases gradually with the material removal. When the removed material thickness is about $23.5 \mathrm{~mm}$, the neutral axis position reaches the lowest point. Subsequently, the neutral axis of the frame parts gradually rises with the material removing. In Figure 4, the leaning dotted line indicates the change of cutting position with material removing, i.e. $z_{1}$ as shown in Figure 2. The neutral axis position line intersects with the cutting position line at $P$ point. Point $P$ is located at $10.5 \mathrm{~mm}$ where the machining position coincides with the neutral axis position. In the region I, the deformation energy of the material removed acts above the neutral axis; in the region II, the deformation energy of the material removed acts below the neutral axis.

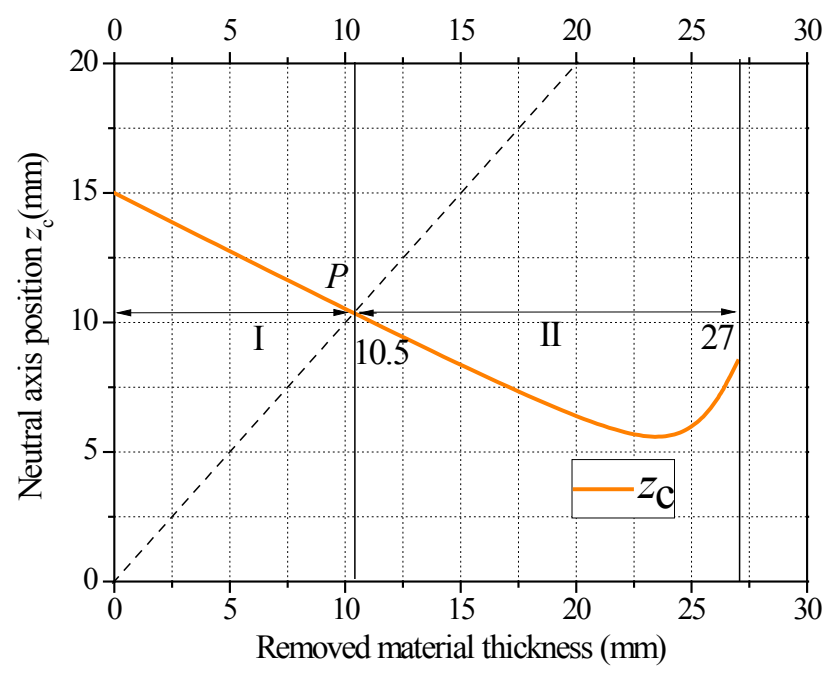

Figure 4 Position of the neutral axis in the machining process

The energy $V_{\varepsilon}$ of the removed material can be obtained from formula (3) (4) and (5). Figure 5 shows the change law of effective deformation energy in rolling direction according to the above analysis. The distribution of initial residual stress of 7050-T7451 aluminum alloy blank is shown by the pink dotted line in the Figure 5. It can be concluded that the compressive stress is in the range of $0 \mathrm{~mm}-2.48 \mathrm{~mm}$ and $12.73 \mathrm{~mm}-27.18 \mathrm{~mm}$. The tensile stress is in the range of $2.48 \mathrm{~mm}-12.73 \mathrm{~mm}$. So, the energy of removed material is divided into three parts, named I, II and III. These three regions correspond to the 
change tendency of energy. In the region I and III, the energy positive increases continuously. In the region II, the energy negative increase continuously. At the position of $2.48 \mathrm{~mm}$ and $12.73 \mathrm{~mm}$, the compressive stress and tensile stress energy of removed material reach the maximum value of $12.1 \mathrm{~J}$ and $-6.2 \mathrm{~J}$ respectively. When the machining is completed, the deformation energy contained in the removed material is $-1.2 \mathrm{~J}$.

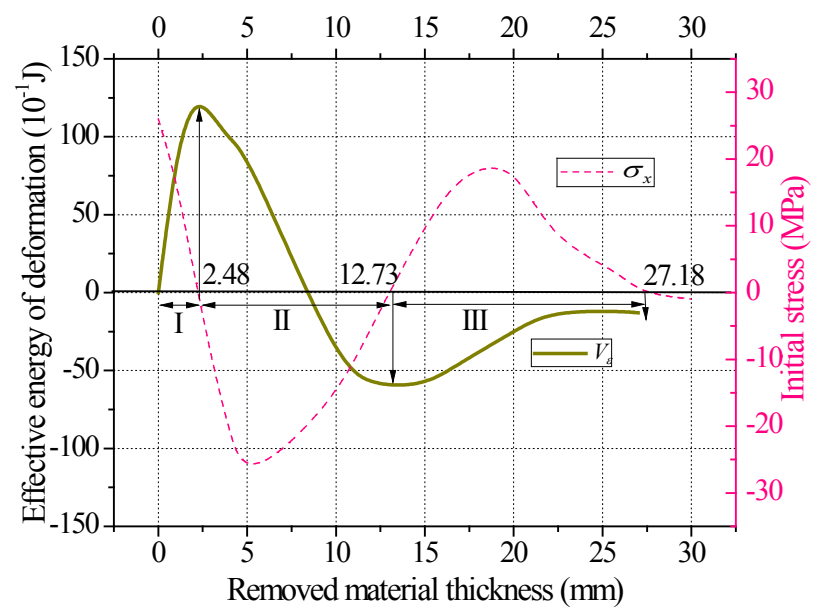

Figure 5 Variation of effective energy of deformation in the machining process

The component is deformed gradually as the material is removed. Assuming that the bending moment acting on both ends of the part is $M$. The relationship between deformation energy and moment and deforming angle is as the following:

$$
V_{\varepsilon}=M \theta / 2
$$

where $\theta$ is deforming angle as shows in Figure 6. It is set up based on the theoretic of mechanics of materials as follows:

$$
\theta=\frac{M L}{E I}
$$

where $E$ is the elastic modulus, $I$ is the inertial moment of $\mathrm{U}$ section, and $E I$ is the bending stiffness.

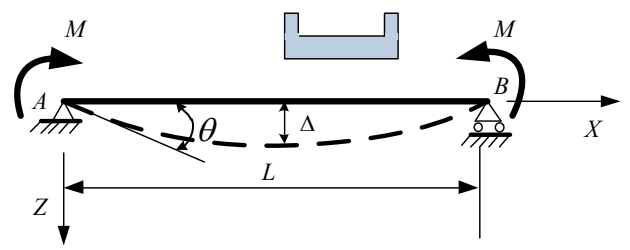

Figure 6 Schematic diagram of component deformation

The maximum deformation $\Delta$ can be obtained by moment area method as the following[28]:

$$
\Delta=\int_{A}^{B} x \frac{M d x}{E I}
$$

Based on the analyses above, deformation are obtained by computer programming. The change of the maximum deformation of the studied case is listed as shown in Figure 7. The deformation law of component is consistent with that of strain energy. The component deformed upward as the removed material is from $0 \mathrm{~mm}$ to $12.73 \mathrm{~mm}$, and downward as the removed material is from $12.73 \mathrm{~mm}$ to $27 \mathrm{~mm}$. The maximum deformation is $0.24 \mathrm{~mm}$ when the component machining finished. The deformation is closely related to the distribution of initial residual stress as above explained.

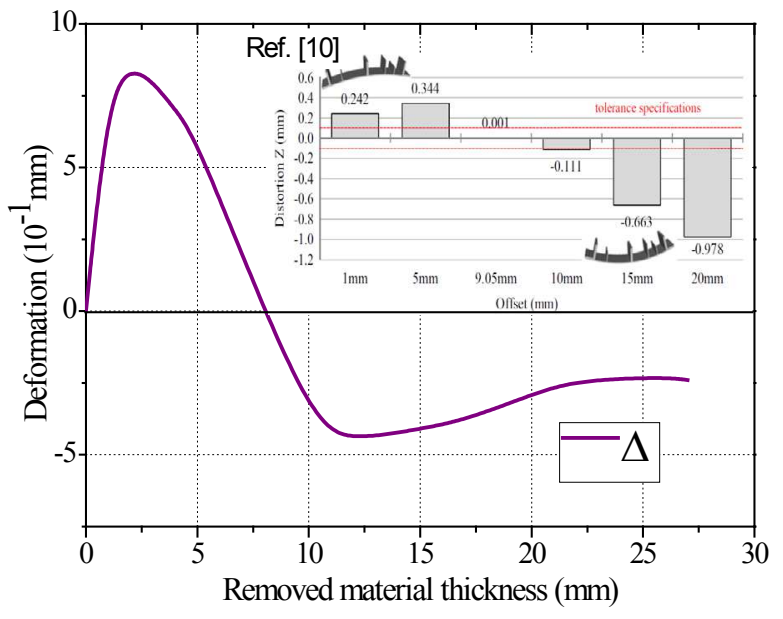

Figure 7 Deformation of single frame part theory model

This theoretical analysis can be used to explain the offset machining results in Ref [10]. The offset was chosen to minimize the machining deformation. The deformation of the aircraft part was achieved from a maximum of about $0.5 \mathrm{~mm}$ to $0.04 \mathrm{~mm}$ for the case with the optimal offset $9.05 \mathrm{~mm}$ in Reference [10]. An inversion in the curvature can be seen by application of an offset of around $9 \mathrm{~mm}$ in the illustration of Figure 7. It confirms the feasibility of the theoretical model of this paper. In Reference [10], the gradient of residual stresses on the upper surfaces region between $0 \mathrm{~mm}$ to $10 \mathrm{~mm}$ is large. This region should be avoided during machining as the reference suggested.

The symmetry of stress distribution can also be used to explain the deformation results as studied in Reference [8]. The deformation obtained by integration will be minimized to zero when the energy of compressive stress is equal to the energy of tensile stress. In Reference [8]. 
The deformation of T-shaped aircraft part decreased with machining asymmetry.

\section{Deformation Calculation of Multiple Frames Component}

\subsection{Machining Deformation Based on FEM}

Due to the large size and manufacturing cost of aircraft monolithic components, it is usually difficult to carry out full-size deformation experiments. FEM deformation analysis is considered to be an economical and effective method for machining deformation. Simulation of machining deformation is performed using FEM software ABAQUS. An aircraft monolithic component is designed based on the real components in Figure 1. A total of 59,910 elements and 67,617 nodes are applied on the model with meshed C3D8R element. The 3-2-1 constraint principle was used for the boundary conditions. Technology of "element birth and death" is applied to simulate the material moving. The mechanical property of the material is listed in Table 1.

Table 1 Mechanical property of 7050-T7451 Al alloy

\begin{tabular}{rcccc}
\hline$E(\mathrm{GPa})$ & $\mu$ & $\sigma_{t}(\mathrm{MPa})$ & $\sigma_{s}(\mathrm{MPa})$ & $\rho_{m}\left(\mathrm{~g} / \mathrm{cm}^{3}\right)$ \\
\hline 71.7 & 0.33 & 469 & 303 & 2.83 \\
\hline
\end{tabular}

Figure 8 is the simplified FEM model and deformation after machining. The maximum deformation of the aircraft monolithic component is $0.42 \mathrm{~mm}$ under the action of initial residual stress only in rolling direction. we can see that the component is concave deformation, and the maximum deformation position is located in the center of the component. The machining deformation is not completely symmetrical due to the influence of the stiffening ribs.

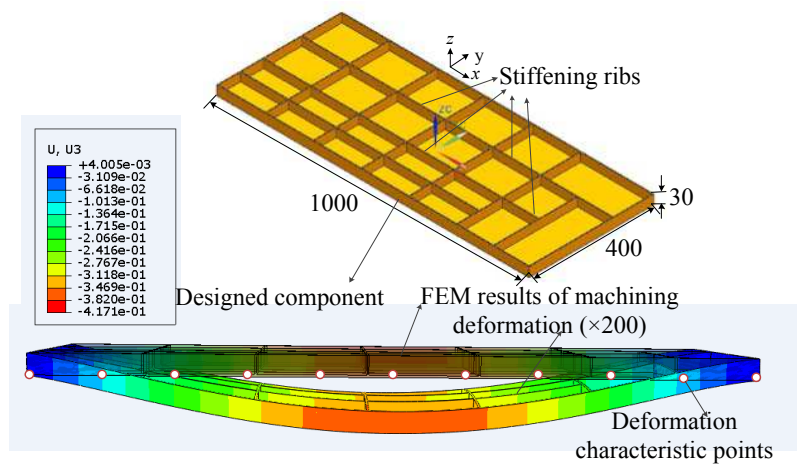

Figure 8 Structure and deformation of FEM model

\subsection{Machining Deformation Based on Energy and Equivalent Stiffness Model}

According to the energy model in Section 2, machining deformation of single frame part is calculated where stiffness is defined as $E I$ in formula (8). However, the effect of stiffening ribs for aircraft monolithic component as shown in Figure 8 is not considered in the energy model of Section 2. Stiffening ribs will greatly improve the rigidity of the component. Machining deformations of thin-walled component with stiffening ribs can be obtained using the equivalent bending stiffness model [19-20].

Based on semi-analytical model of equivalent bending stiffness, the effect of stiffening rib layout is converted to equivalent thickness. A simply-supported component constraint is applied to the model. Uniform load $F$ $\left(1 \times 10^{-3} \mathrm{MPa}\right)$ in $z$ direction is applied to the upper surface. Then, a small linear deformation problem is solved by ABAQUS static analysis, and the maximum deformation $D_{d i s}$ is obtained. The equivalent thickness $h_{e q v}$ and equivalent bending stiffness $D_{\text {eqv }}$ of the aircraft monolithic component can be obtained as:

$$
\begin{gathered}
h_{e q v}=\left(\frac{4 F L^{3}}{D_{d i s} \cdot E \cdot W}\right)^{1 / 3} \\
D_{e q v}=\frac{E h_{e q v}{ }^{3}}{12\left(1-\mu^{2}\right)}
\end{gathered}
$$

where $L$ and $W$ are the length and width of the component respectively. Taking the model of Figure 8 as investigation case, the removed material is divided into 9 layers, each layer is $3 \mathrm{~mm}$. Then the material is removed layer by layer. The deformation is shown in Table 2 when the material is removed gradually. The equivalent thickness of aircraft monolithic component is obtained by formula (10).

Table 2 The deformation when the material is removed

\begin{tabular}{cccccccccc}
\hline Lays & 1 & 2 & 3 & 4 & 5 & 6 & 7 & 8 & 9 \\
\hline $\begin{array}{c}D_{\text {dis }} \\
\left(10^{-1} \mathrm{~mm}\right)\end{array}$ & 0.55 & 0.86 & 1.17 & 1.53 & 1.92 & 2.31 & 2.65 & 2.89 & 3.43 \\
\hline
\end{tabular}

The stiffness of blank plate is calculated by formula (11), where $h_{\text {eqv }}$ is the thickness of the blank plate without stiffening ribs. In Figure 9, the cyan curve represents the change law of theoretical stiffness as the plate thickness decreases. It decreased gradually as third power function of the thickness value of the blank.

According to the above mentioned equivalent stiffness 
model and the data in Table 2, the stiffness of the component after removing each layer material can be calculated.

In Figure 9, the black symbol curve represents the change of equivalent bending stiffness. Equivalent stiffness decreased non-linearity with the material removing. $D_{d i s}$ is almost equivalent compared with theory stiffness of blank plate when the material removed at the upper region of $9 \mathrm{~mm}$. However, the differences between them gradually became obvious after that. This is because of the effect of the stiffening ribs. The theoretical stiffness for $30 \mathrm{~mm}$ thickness blank is $1.81 \times 10^{5} \mathrm{~N} / \mathrm{m}$. The equivalent stiffness of the finished component is obtained as $2.01 \times 10^{4} \mathrm{~N} / \mathrm{m}$. The stiffness decreased by $88.9 \%$.

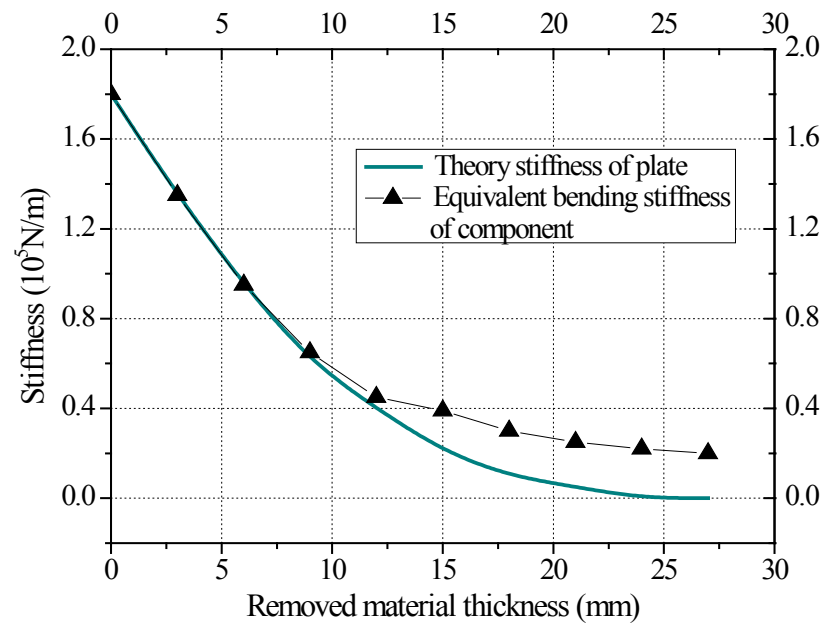

Figure 9 Stiffness evolution during material removal

Aircraft monolithic component machining deformation can be obtained using the energy model and equivalent bending stiffness model. For comparing, 11 deformation characteristic points along $x$ direction are picked up as shown in Figure 8. The deformation curve of these FEM characteristic points and energy model are listed in Figure 10. It can be seen that the machining deformation law appeared downward bending in the middle and warped at both ends. The curves of theoretical results are symmetrical and the maximum value of deformation is $0.51 \mathrm{~mm}$. FEM results are smaller than the theory results. The maximal error was $17.6 \%$, which is in the range of acceptable.

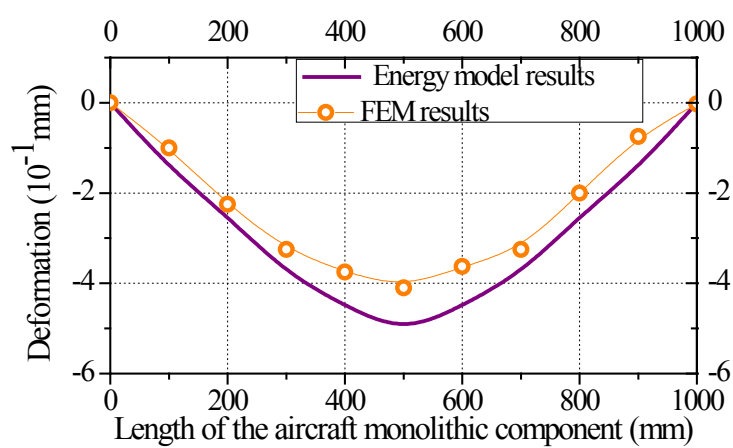

Figure 10 Deformation of aircraft monolithic component along $\mathrm{x}$ direction

\section{Verification of Energy Model}

\subsection{Experiment Setup}

Experiments were performed on 7050-T7451 aluminium alloy blank of thickness $60 \mathrm{~mm}$ provided by Kaiser Aluminum \& Chemical Corp., USA. The specimen is cut by wire electrical-discharge machining (WEDM) from blank based on the design of single frame part as shown in Figure 1. WEDM produce less additional residual stress than traditional mechanical cutting, and its effect on the initial residual stress in the blank is ignored.

MC1200 5-axis vertical machining centre is used for the machining work. The detailes of the experimental conditions are presented in Table 3. Distortion data are obtained by Hexagon MICRO-HITE 3D CMM (Hexagon Metrology (Qingdao) Co., Ltd.). The accuracy of this coordinate measuring machine is $4 \mu \mathrm{m}$. In the experiment, the cutting depth is set as $3 \mathrm{~mm}$. The specimen is unloading clamped and deformation measured after each layer of cutting depth is removed. There are six characteristic lines with the equal distance of $10 \mathrm{~mm}$ in the bottom of the specimen, and the average value is taken as analysis data to ensure the accuracy of the measurement. Machining and deformation measurement are shown in Figure 11. 

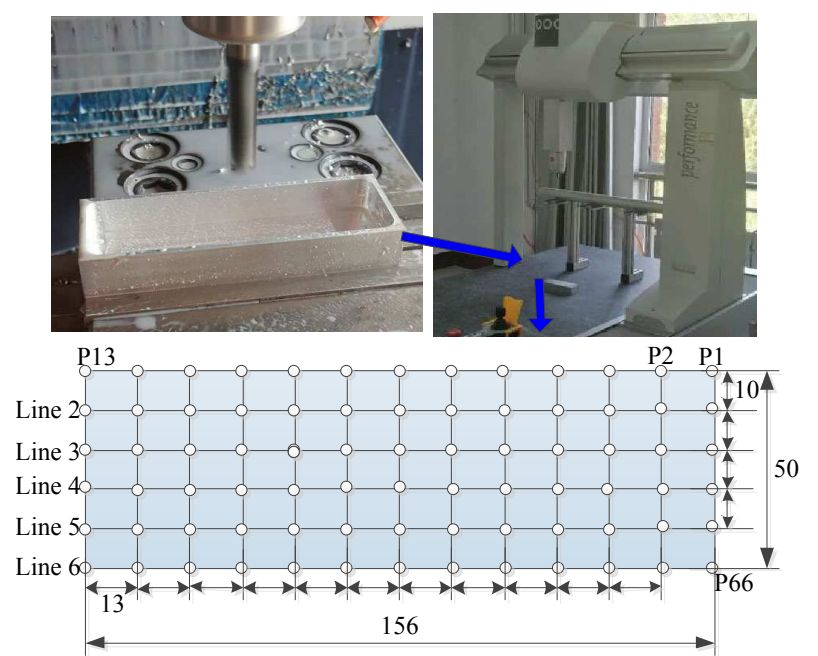

Figure 11 Schematic diagram of experiment

Table 3 The experimental conditions

\begin{tabular}{cc}
\hline CNC & MC1200 5-axis vertical machining centre \\
\hline Cutting tool & Solid cemented carbide \\
\hline Machining state & Wet, Down milling \\
\hline & $v=628 \mathrm{~m} / \mathrm{min}$ \\
\cline { 2 - 2 } Machining & $f_{z}=0.06 \mathrm{~mm}$ \\
\cline { 2 - 2 } parameters & $a_{p}=3 \mathrm{~mm}$ \\
\cline { 2 - 2 } & $a_{e}=12 \mathrm{~mm}$ \\
\hline
\end{tabular}

\subsection{Results}

For comparison, the FEM model of machining deformation for the single frame part is established using the method described in Section 3. Figure 12 shows that the maximum deformation evolution of the component by the energy model, experiment and FEM in the process of removing material. The purple line is the theory results of the energy model, the orange circular point is the FEM results, and the black line with square symbols is the experimental data.

It is can be seen that the deformation law of the experiment results is consistent with the energy model and FEM results. Part shows up-bending deformation when the first two layers of material are removed. Then, it shows down-bending deformation when the last seven layers of material are removed. Deformation law depends on the initial residual stress distribution characteristics. This means that it is determined by the energy in the removed material as discussed in Section 2.

The maximum deformation data of single frame part obtained by experiment are larger than that calculated by the energy model. However, it is lesser than the energy model results when the first two layers of material are removed. The final deformation is $0.38 \mathrm{~mm}$ and $0.24 \mathrm{~mm}$ in experiment and energy model results. The relative error between the experiment and theoretical data is about $36.8 \%$. The experiment deformation is the coupling action of energy in rolling direction and transverse direction. Energy model results do not consider the effect of energy in transverse direction. The coupling effect of initial residual stress between different direction is not the focus of this paper.

Deformation results of theoretical model and FEM are almost identical when the part acted under stress in rolling direction. However, the energy model is a more intuitive new view than computer numerical calculation. It may reduce the FEM calculation time cost in sometimes.

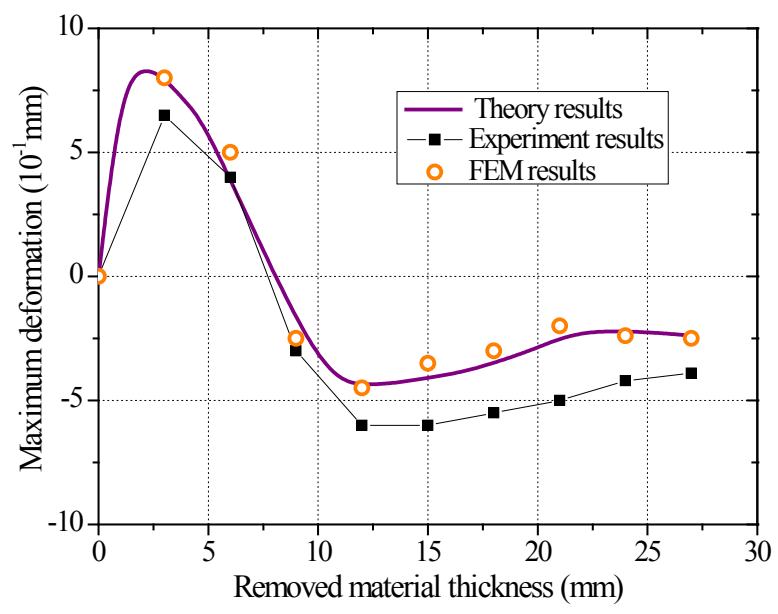

Figure 12 Maximum deformation evolution during material removed

Figure 13 shows the machining deformation of the single frame part by energy model, FEM and experimental data. They present bending deformation along the length direction. FEM data show good agreement with the analytical model results. The deformation curves obtained from the experimental data are larger than those obtained from FEM and theoretical data. The machining deformation of part is affected by many factors such as cutting heat, cutting force, cutting parameters and fixture layout. The influence of these factors on machining deformation is neglected in the energy model. This will lead to some errors between the experimental results and the numerical results. 


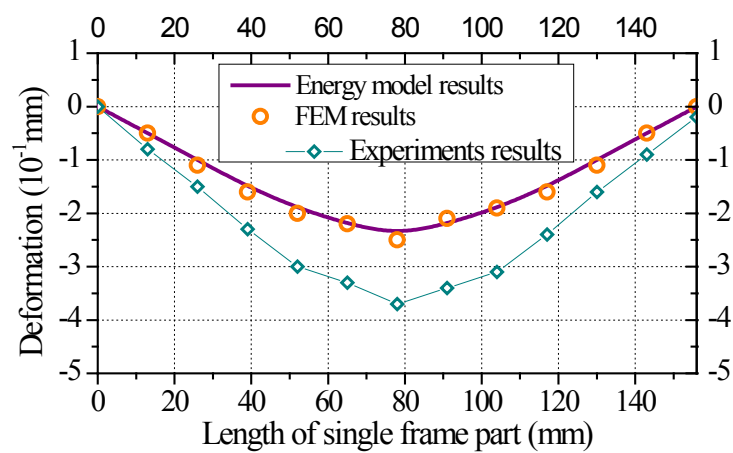

Figure 13 Deformation comparison between energy model, FEM and experiment results

\section{Conclusions}

In this paper, analytical model of the machining deformation evolution is established based on the energy method. FEM is used to study the machining deformation of aircraft monolithic components combining with the equivalent stiffness. Theory model and FEM results are validated by experiment. The most obvious finding can be drawn from this investigation:

(1) The deformation energy of aircraft monolithic component equates to the energy in the removed material. The energy depends on the distribution and characteristics of the initial residual stress in the blank. Moreover, the position of the center axis of the structure will also affect the machining deformation. The turning point of the initial residual stress from compressive to tensile correspond to the turning points of the deformation energy. It determines the deformation type of aircraft monolithic component for lay by lay machining.

(2) Equivalent stiffness of aircraft monolithic component decreased non-linearity with the removed material thickness. Machining deformation of it is calculated based on the energy theory and equivalent stiffness model. The theoretical results are consistent with the FEM results. Results shown that the machining deformation appeared downward bending in the middle and warped at both ends in rolling direction. This is confirmed by both theory, FEM and experiment results.

(3) The energy analysis model proposed in this study has certain limitations, such as the coupling effects of normal residual stress in different directions and shear stress are ignored. However, it provides a reference for further research on machining deformation of aircraft monolithic component.

\section{Declaration}

\section{Acknowledgements}

Not applicable.

\section{Funding}

Supported by National Natural Science Foundation of China (Grant No. 51605037), the Natural Science Foundation of Shandong Province (No.ZR2016EEP04)

\section{Authors' contributions}

The author' contributions are as follows: $\mathrm{XH}$ was in charge of the whole trial and designed the study; XL wrote the manuscript; WS assisted with sampling and laboratory analyses; XL and $\mathrm{BC}$ provided guidance and discussion in theory; DW and GD performed the experiments. All authors read and approved the final manuscript.

\section{Competing interests}

The authors declare no competing financial interests.

\section{Consent for publication}

Not applicable

\section{Ethics approval and consent to participate}

Not applicable

\section{References}

[1] F F Yu, G L Zhang, Y F Rao, et al. Principal face-based recognition approach for machining features of aircraft integral panels. China Journal of Mechanical Engineering, 2011, 24(6):976-982.

[2] K F Zhang, H Cheng, Y LI. Riveting process modeling and simulating for deformation analysis of aircraft's thin-walled sheet-metal parts. Chinese Journal of Aeronautics, 2011, 24:369-377.

[3] H Y Dong, Y L Ke. Study on machining deformation of aircraft monolithic component by FEM and experiment. Chinese Journal of Aeronautics, 2006, 19(3):247-54.

[4] Z J Wang, W Y Chen, Y D Zhang, et al. Study on the machining distortion of thin-walled part caused by redistribution of residual stress. Chinese Journal of Aeronautics, 2005, 18(2):175-9.

[5] J H Yu, Z T Chen. A control method of machining distortion using adaptive fixture with dual arm. Acta Aeronautica et Astronautica Sinica, 2016, 5:1657-1665 (Chinese).

[6] X M Huang, J Sun, J F Li. Finite element simulation and e xperimental investigation on the residual stress-related monolithic component deformation. The International Journal of Advanced Manufacturing Technology, 2015, 77 (5-8):1035-1041.

[7] X M Huang, J Sun, J F Li. Effect of initial residual stress and machining induced residual stress on the deformation of aluminium alloy plate. Strojniski Vestnik-Journal of Mechannical Engineering, 2015, 61(2):131-137.

[8] Z Zhang, L Li, Y F Yang, et al. Machining distortion minimization for the manufacturing of aeronautical structure. The International 
Journal of Advanced Manufacturing Technology, 2014, 73:1765-1773.

[9] H C Ye, G H Qin, H M Wang, et al. A machining position optimization approach to workpiece deformation control for aeronautical monolithic components. The International Journal of Advanced Manufacturing Technology, 2020, 109:299-313.

[10] X Cerutti, K Mocellin. Influence of the machining sequence on the residual stress redistribution and machining quality: analysis and improvement using numerical simulations. The International Journal of Advanced Manufacturing Technology, 2016,83:489-503.

[11] G C Ding, T Zhang, H G Li, et al. Analysis of the processing sequence on airframe structures machining deformation. International Journal of Engineering Technologies and Management Research, 2020, 7(6):1-10.

[12] X Z Hao, Y G Li, C Huang, et al. An allowance allocation method based on dynamic approximation via online inspection data for deformation control of structural parts. Chinese Journal of Aeronautics, 2020, DOI:10.1080/0951192X.2018.1529431.

[13] C Mikel, P Roberto, V Fernando, et al. Residual stress and distortion modeling on aeronautical aluminum alloy parts for machining sequence optimization. The International Journal of Advanced Manufacturing Technology, 2020, 110:1219-1232.

[14] L X Lu, J Sun, X Han, et al. Load prediction method of rolling distortion correction for monolithic aeronautical components based on energy method. Acta Aeronautica et Astronautica Sinica, 2017,38:421326 (Chinese).

[15] $\mathrm{L} \mathrm{X} \mathrm{Lu,} \mathrm{J} \mathrm{Sun.} \mathrm{Investigation} \mathrm{on} \mathrm{distortion} \mathrm{mechanism} \mathrm{and}$ correcting load calculation method for aluminum beam structure by bilateral rolling process. Procedia CIRP, 2016,57:781-786.

[16] C F Yao, J Y Zhang, M C Cui, et al. Machining deformation prediction of large fan blades based on loading uneven residual stress. The International Journal of Advanced Manufacturing Technology, 2020,107:4345-4356.

[17] B Denkena, L G León, J Köhler. Influence of high performance cutting operations on the residual stresses of aluminum structural workpieces. Proceedings of the 25th International Congress of the aeronautical sciences, Metz, France,2006.

[18] J G Li, S Q Wang. Distortion caused by residual stresses in machining aeronautical aluminum alloy parts: recent advances. The International Journal of Advanced Manufacturing Technology, 2017, 89:997-1012.

[19] Li BH, Gao HJ, Deng HB, Pan H, Wang BG. Investigation on the influence of the equivalent bending stiffness of the thin-walled parts on the machining deformation. The International Journal of Advanced Manufacturing Technology, 2019, 101:1171-1182.

[20] X M Huang, H W Yang, J X Li. The analysis of stiffness evolution for aeronautical monolithic beam machining process. Journal of Binzhou University, 2017, 33(4):5-10 (Chinese).

[21] X M Huang, J Sun, J F Li. Mathematical modeling of aeronautical monolithic component machining distortion based on stiffness and residual stress evolvement. Chinese Journal of Mechanical Engineering, 2017, 53(9):201-208 (Chinese).

[22] G Z Sun. Research on machining deformation simulation and control technology of large complex thin-walled structural parts[dissertation]. Lang Fang: North China Institute of Aerospace Engineering, 2015(Chinese).

[23] Z Zhang. Research on Residual Stress and Machining Distortion of Aeronautic Weak Rigidity in Aluminum Structure[dissertation]. Nan Jing: Nanjing University of Aeronautics and Astronautics,
2015(Chinese).

[24] Y F Yang, L X Fan, L Li, et al. Energy principle and material removal sequence optimization method in machining of aircraft monolithic parts. Chinese Journal of Aeronautics, 2020, 33(10):2770-2781.

[25] H S Shang. Prediction of the dimensional instability resulting from machining of residually stressed components[dissertation]. Rabbock Texas: Texas Tech University, 1995.

[26] C A Zhou, J Sun, W D Li, et al. The measurement of original residual stress in aircraft aluminum alloy. Mechanical Science and Technology for Aerospace Engineering, 2014, 33(8),1251-1254.

[27] X M Huang. Deformation mechanism and prediction of aluminum alloy monolithic component in the milling[dissertation]. Ji'nan: Shandong University, 2015 (Chinese).

[28] L M Zhang, C X He, F T Zhang. Solving the bending problem of beam based on bending moment diagram area method. Experiment Science and Technology, 2017, 15(3):25-28(Chinese).

\section{Biographical notes}

Xiao-Ming Huang, born in 1981, is currently an associate professor at Mechatronics Engineering Department, Binzhou University, China. He received his $\mathrm{PhD}$ degree from Shangdong University, China, in 2015. His research interests is machining of aircraft monolithic components.

Tel: +86-18306490081, E-mail: hxm2552@163.com

Xiao-Liang Liu, born in 1981, is currently an associate professor at Mechatronics Engineering Department, Binzhou University, China. He received his PhD degree from State Key Laboratory of Mechanics and Control of Mechanical Structures, Nanjing University of Aeronautics and Astronautics, China, in 2019.

E-mail: jasonxlliu@163.com

Wei-Tao Sun, born in 1986, is currently a lecturer at Mechatronics Engineering Department, Binzhou University, China. He received his $\mathrm{PhD}$ degree on mechanical engineering, Dalian University of Technology, China, in 2019.

E-mail: sun_wei_tao@163.com

Jia-Xing Li, born in 1990, is currently a lecturer at Mechatronics Engineering Department, Binzhou University, China. He received his master degree on aviation engineering in Civil Aviation University of China, China, in 2016.

E-mail: 981764286@qq.com

Yong-Bin Chen, born in 1984, is currently an associate professor at Mechatronics Engineering Department, Binzhou University, China. He received his $\mathrm{PhD}$ degree from College of Aerospace Engineering, Nanjing University of Aeronautics and Astronautics, China, in 2018. His research interests include aircraft design, aircraft manufacturing engineering.

E-mail: chenyongbinfly@126.com 
De-Chen Wei, born in 1985, is currently an associate professor at Mechatronics Engineering Department, Binzhou University, China. He received his $\mathrm{PhD}$ degree from College of Aerospace Engineering, Nanjing University of Aeronautics and Astronautics, China, in 2017. His research interests include non-traditional machining, aircraft manufacturing engineering.

E-mail: $372571316 @ q q . c o m$

Gui-Chu Ding, born in 1994, is currently a master candidate at Mechanical Engineering Department, Tianjin Vocational Technology Normal University, China. His research interests is prediction and control of machining deformation on aircraft monolithic components.

E-mail: $372571316 @ q q . c o m$ 
Figures

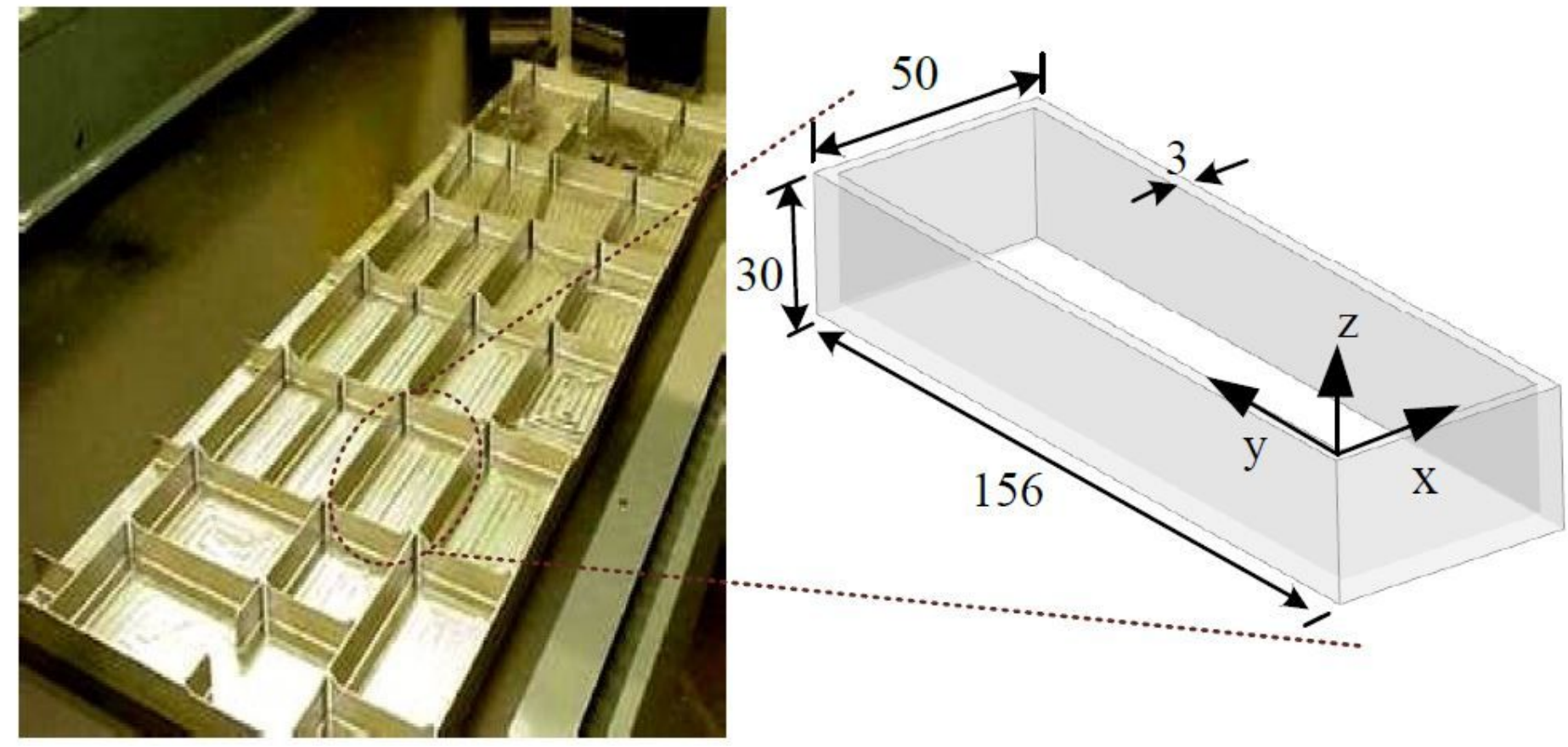

Figure 1

Aircraft monolithic component and single frame part 

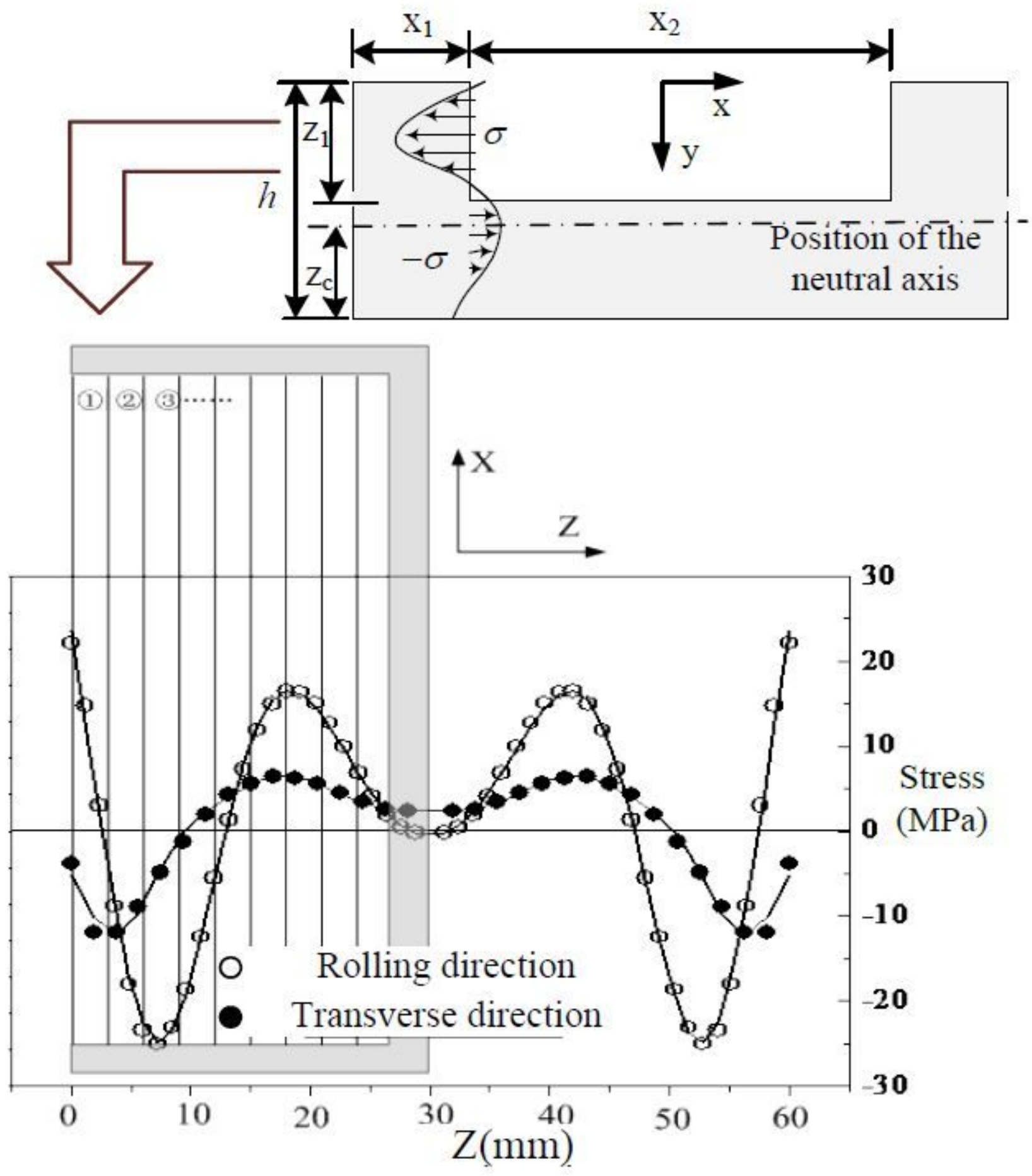

Figure 2

Initial residual stress of aluminum alloy blank 


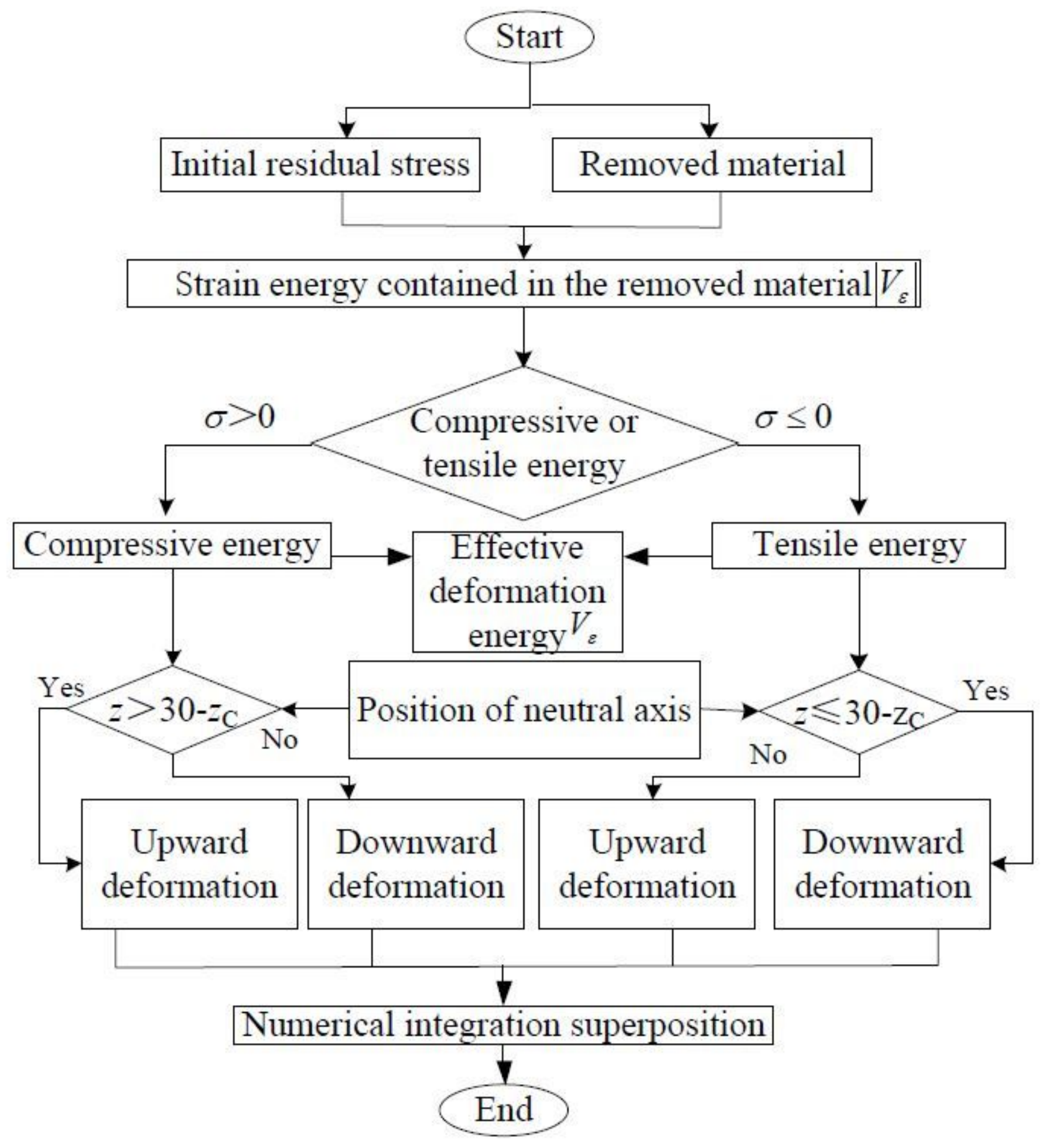

Figure 3

Flow chart of component deformation analysis 


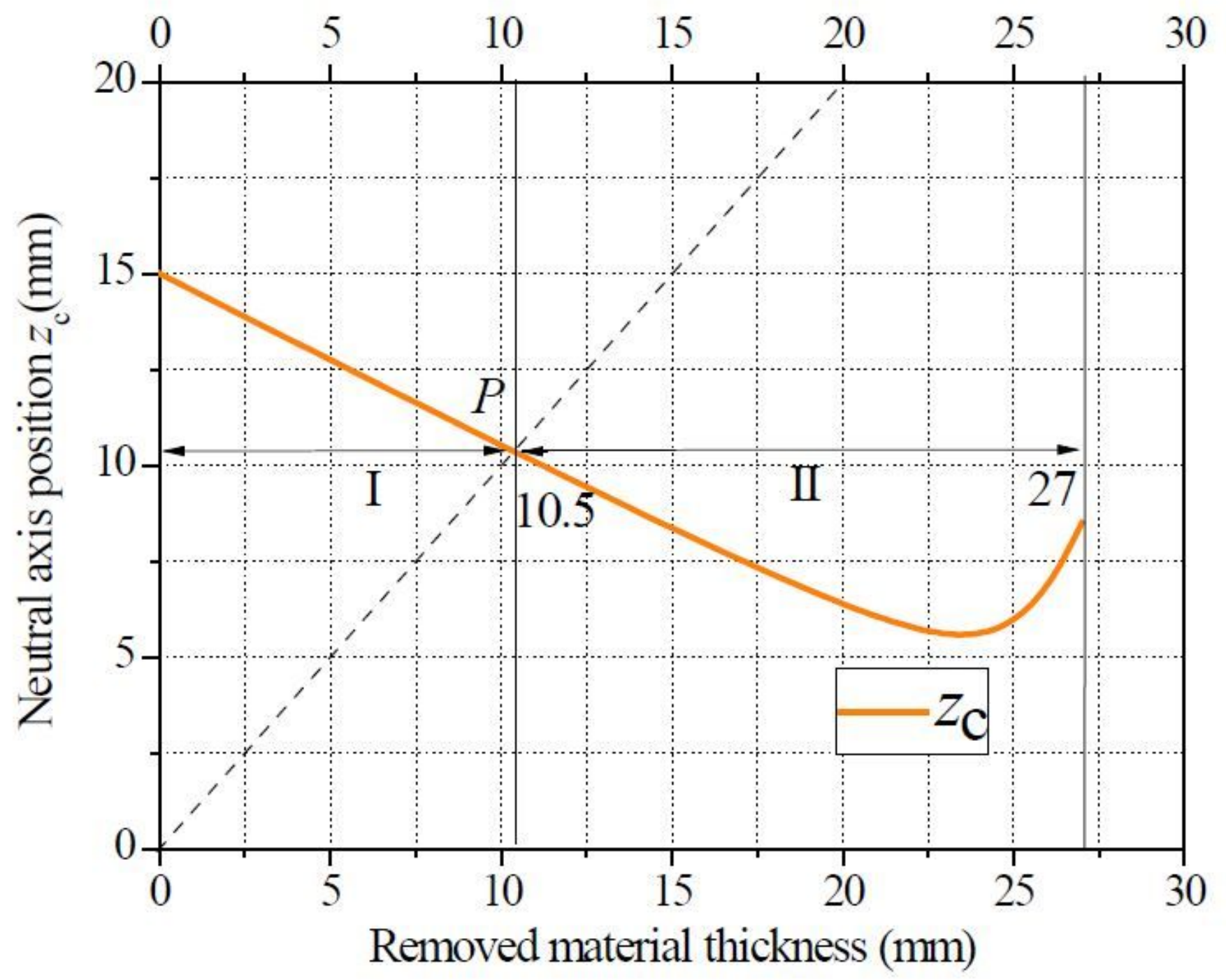

Figure 4

Position of the neutral axis in the machining process 


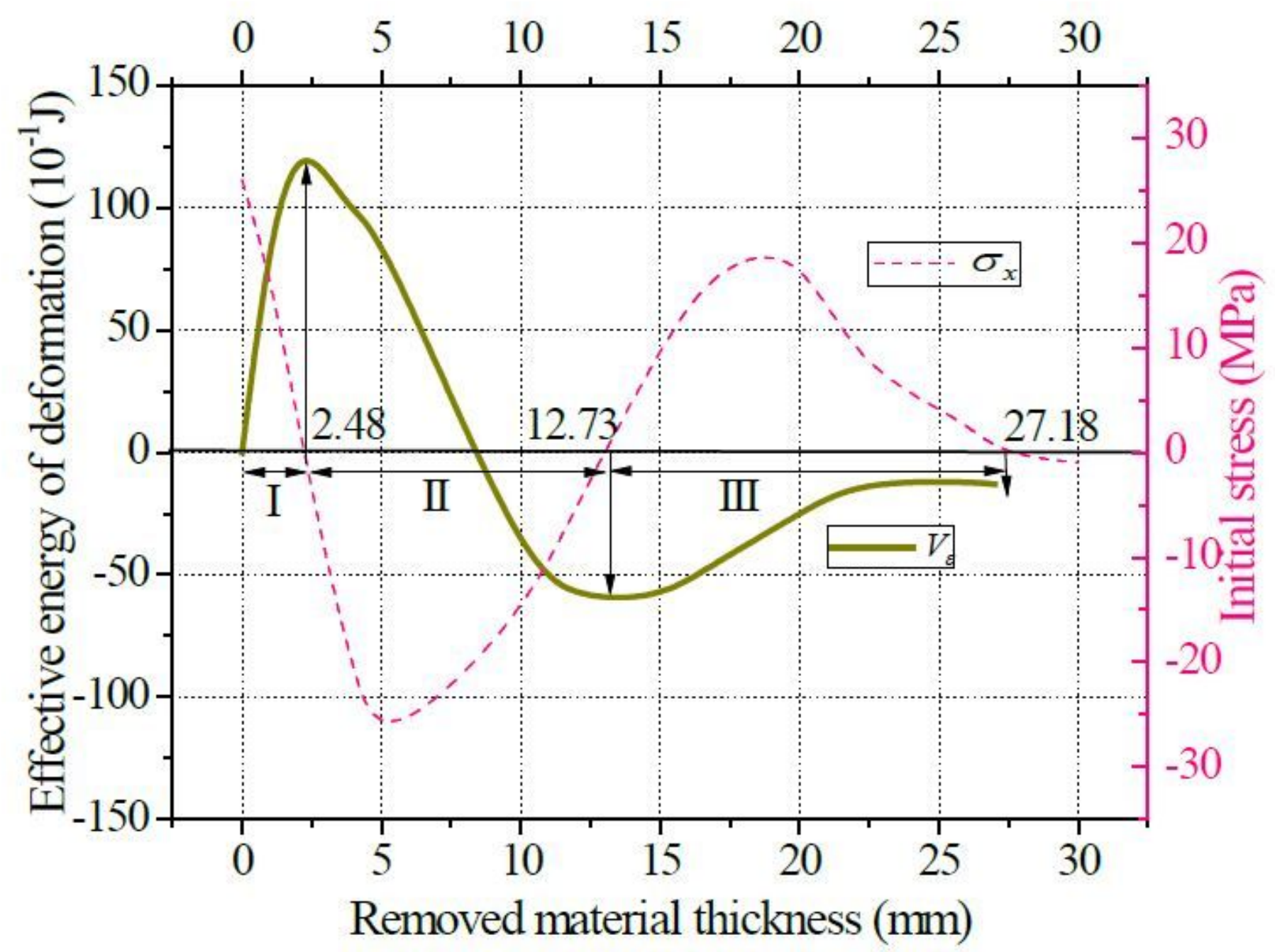

Figure 5

Variation of effective energy of deformation in the machining process

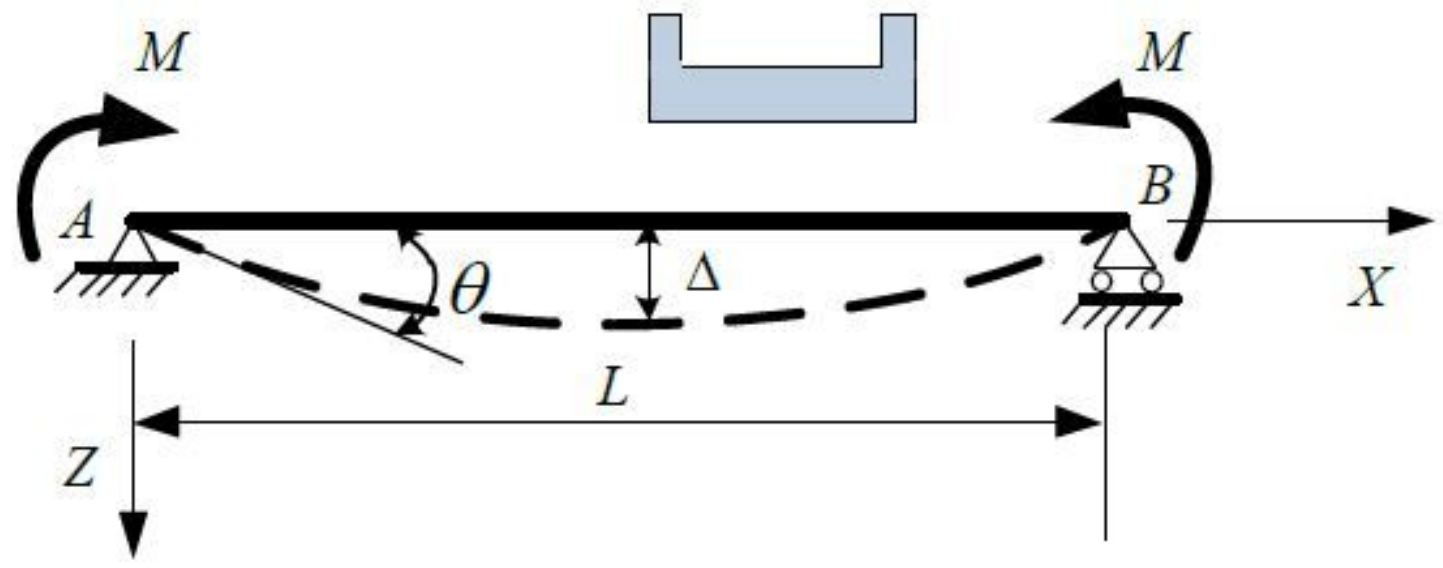

Figure 6 
Schematic diagram of component deformation

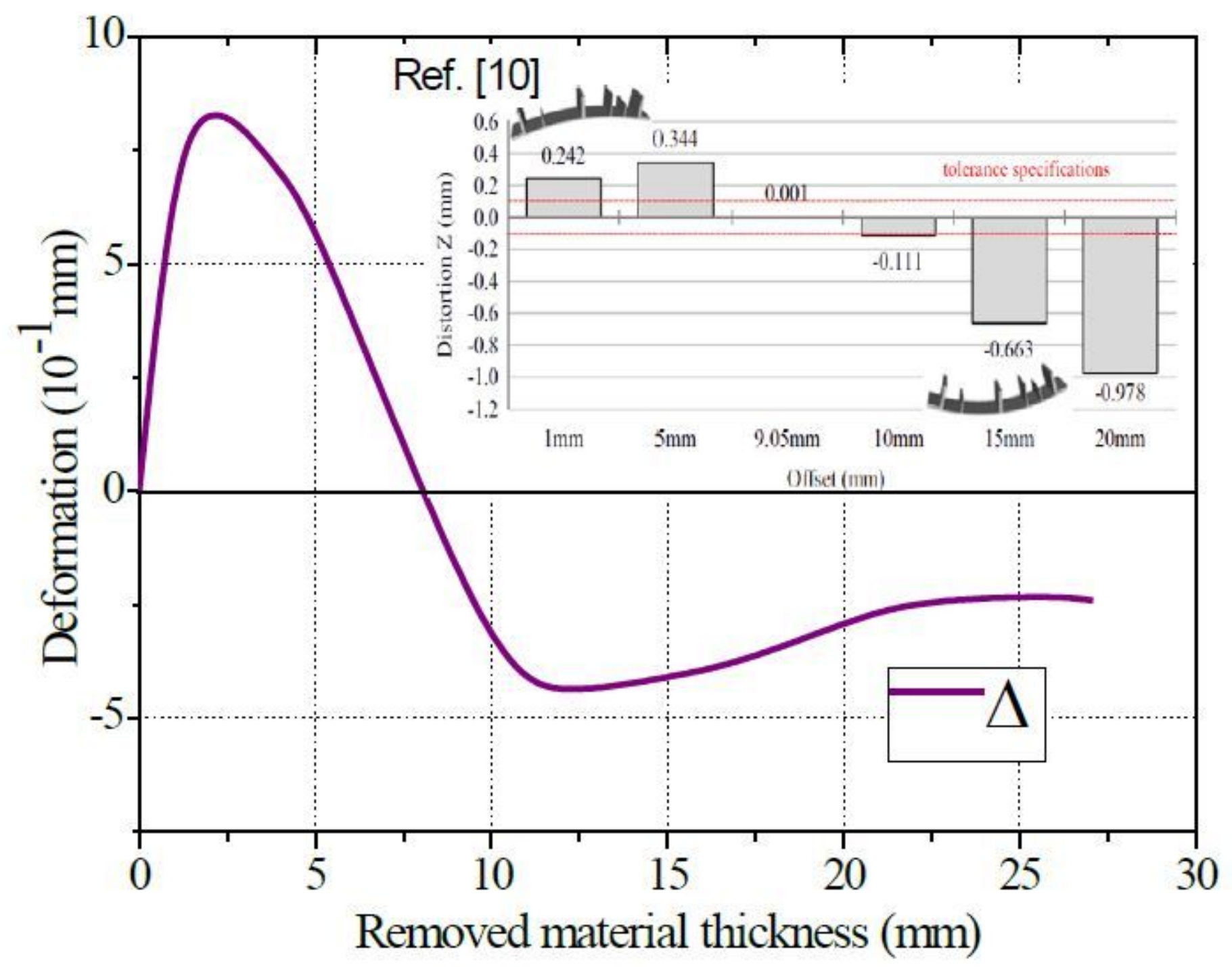

Figure 7

Deformation of single frame part theory model 


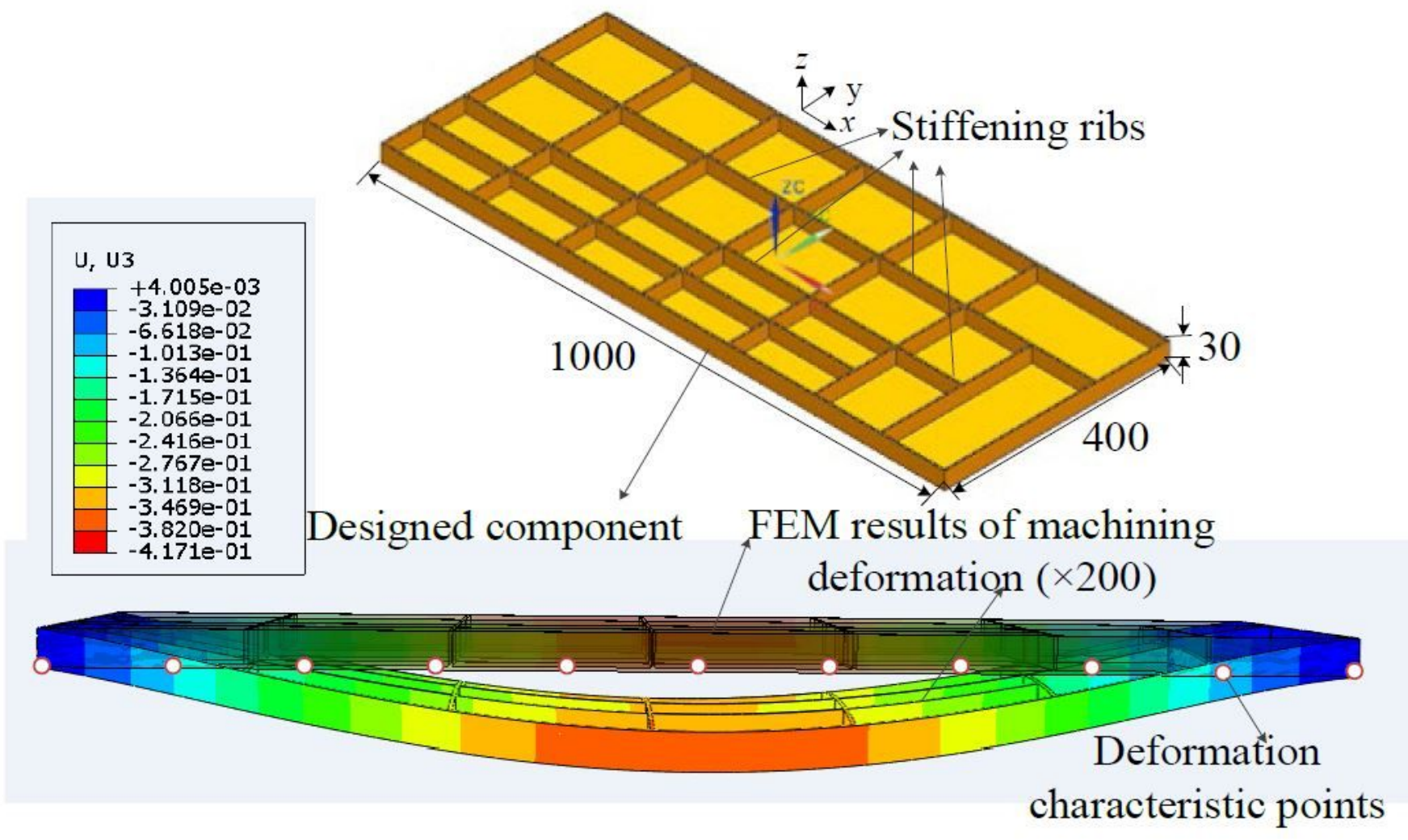

Figure 8

Structure and deformation of FEM model 


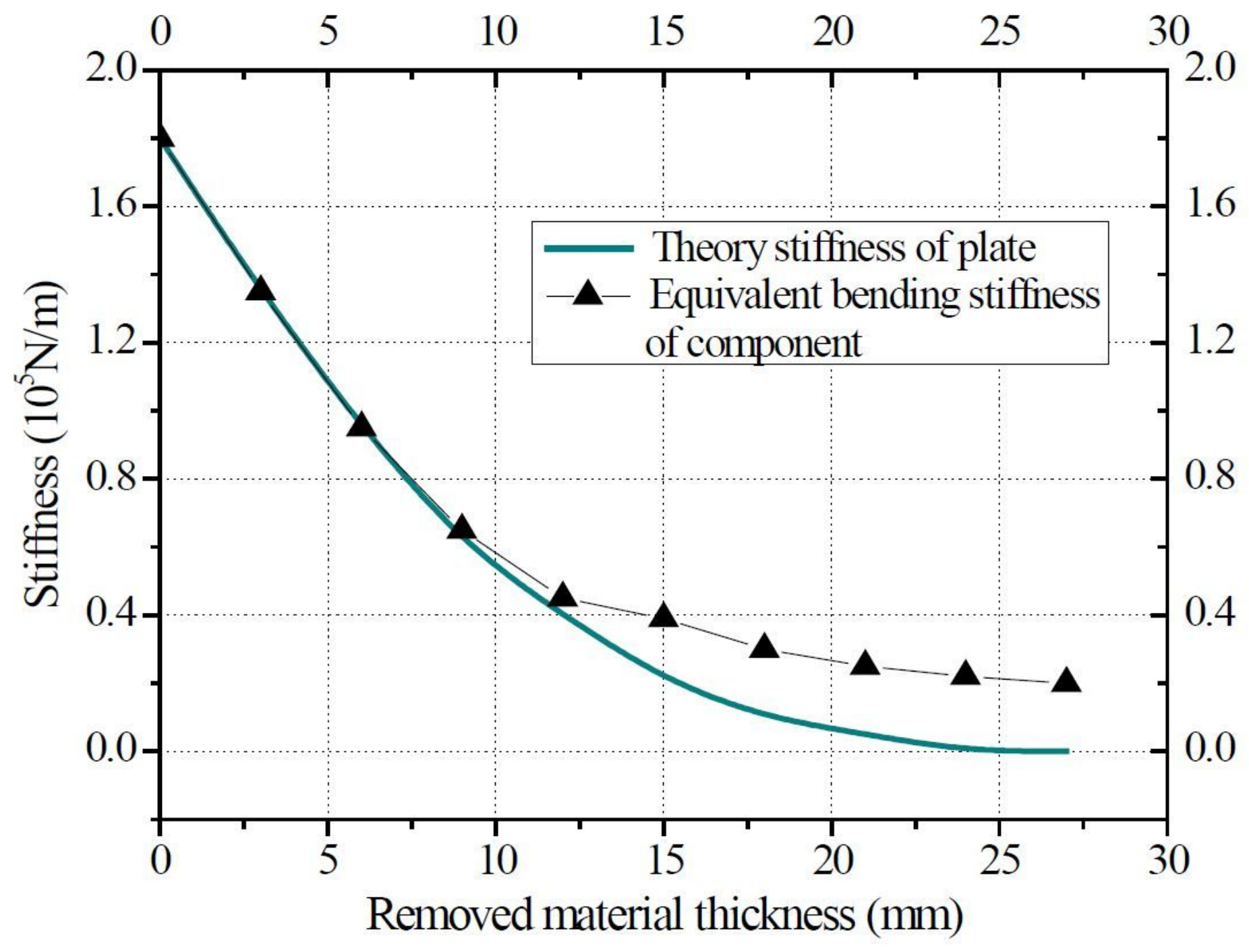

Figure 9

Stiffness evolution during material removal 


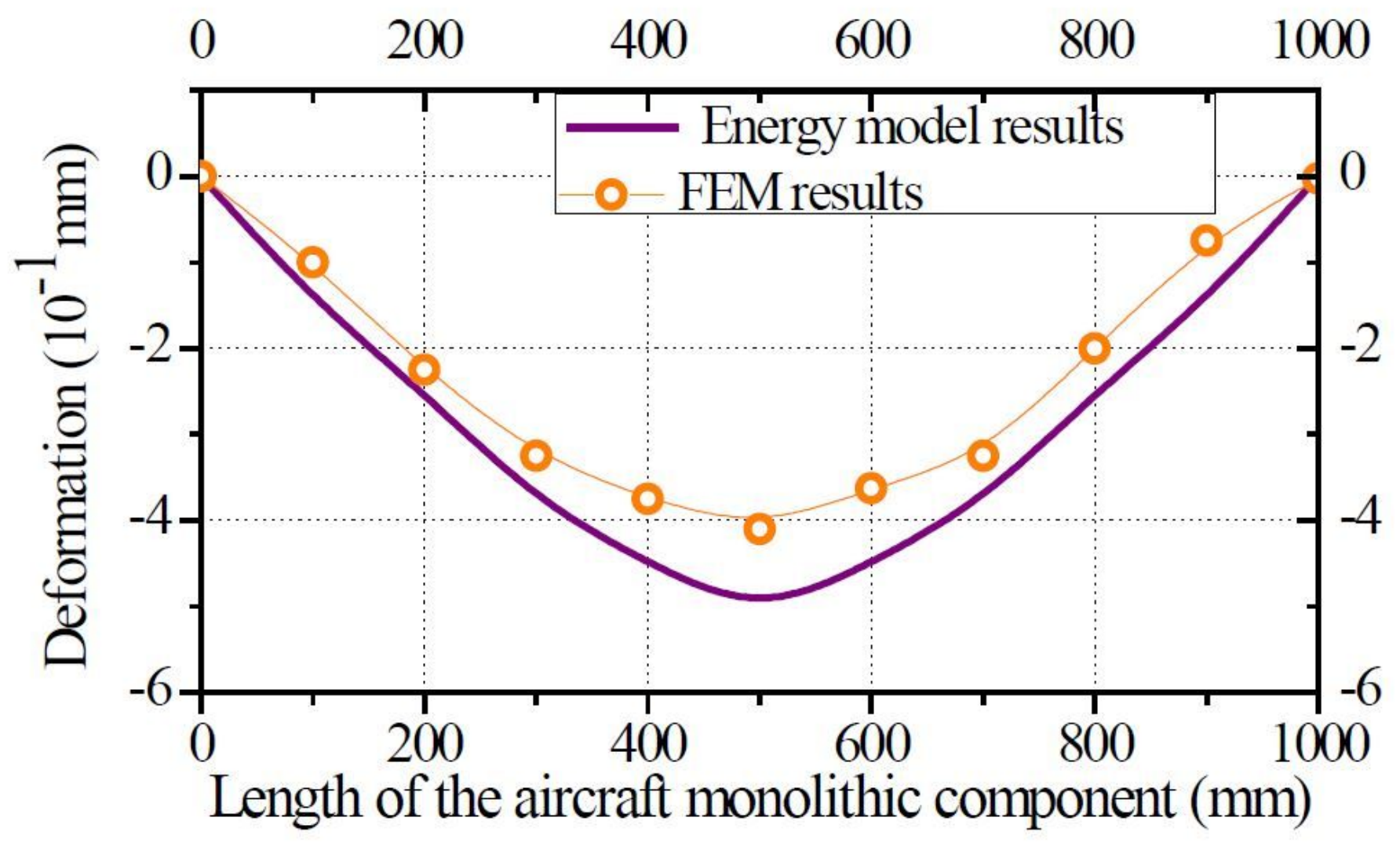

Figure 10

Deformation of aircraft monolithic component along $\mathrm{x}$ direction 

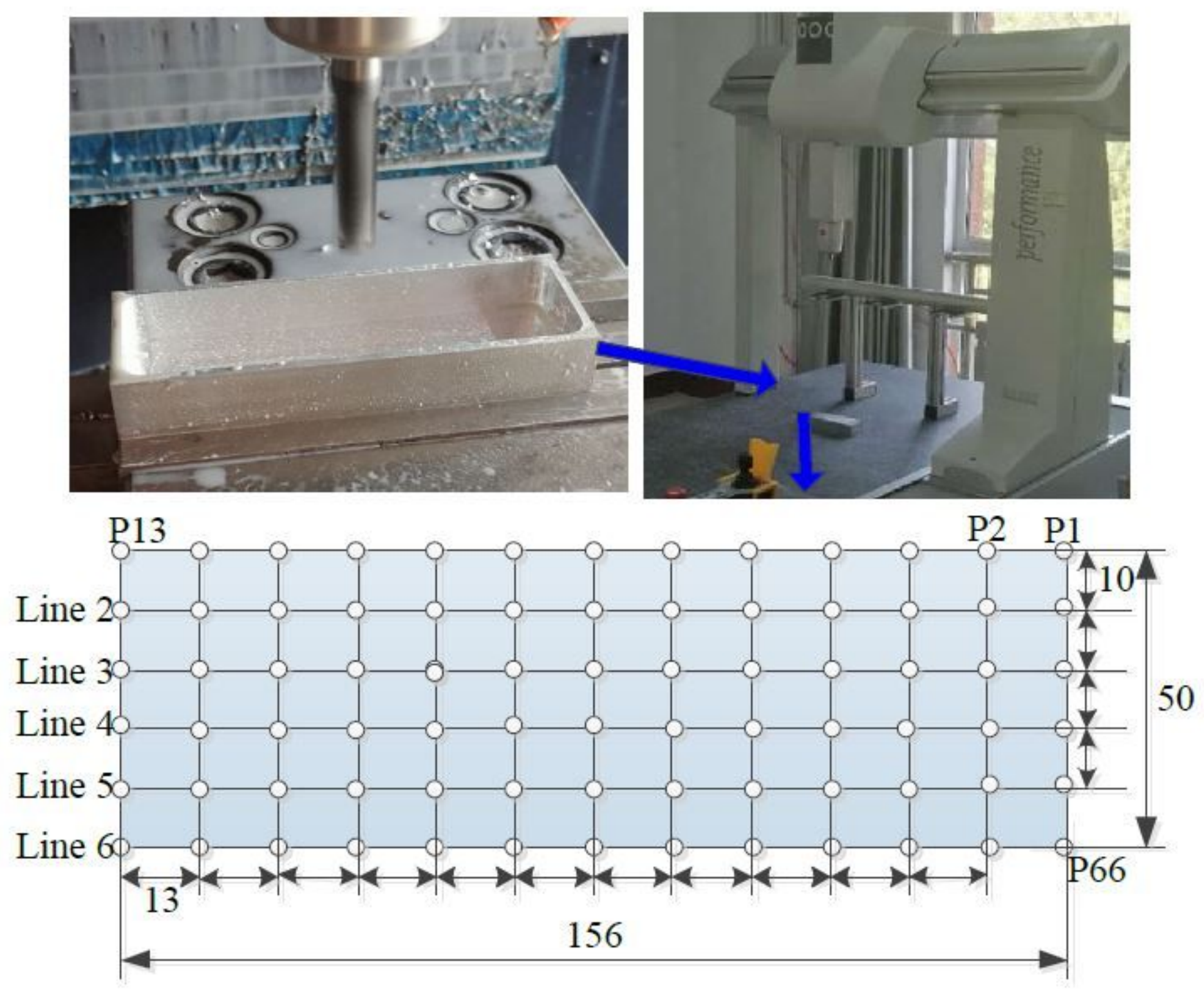

Figure 11

Schematic diagram of experiment 


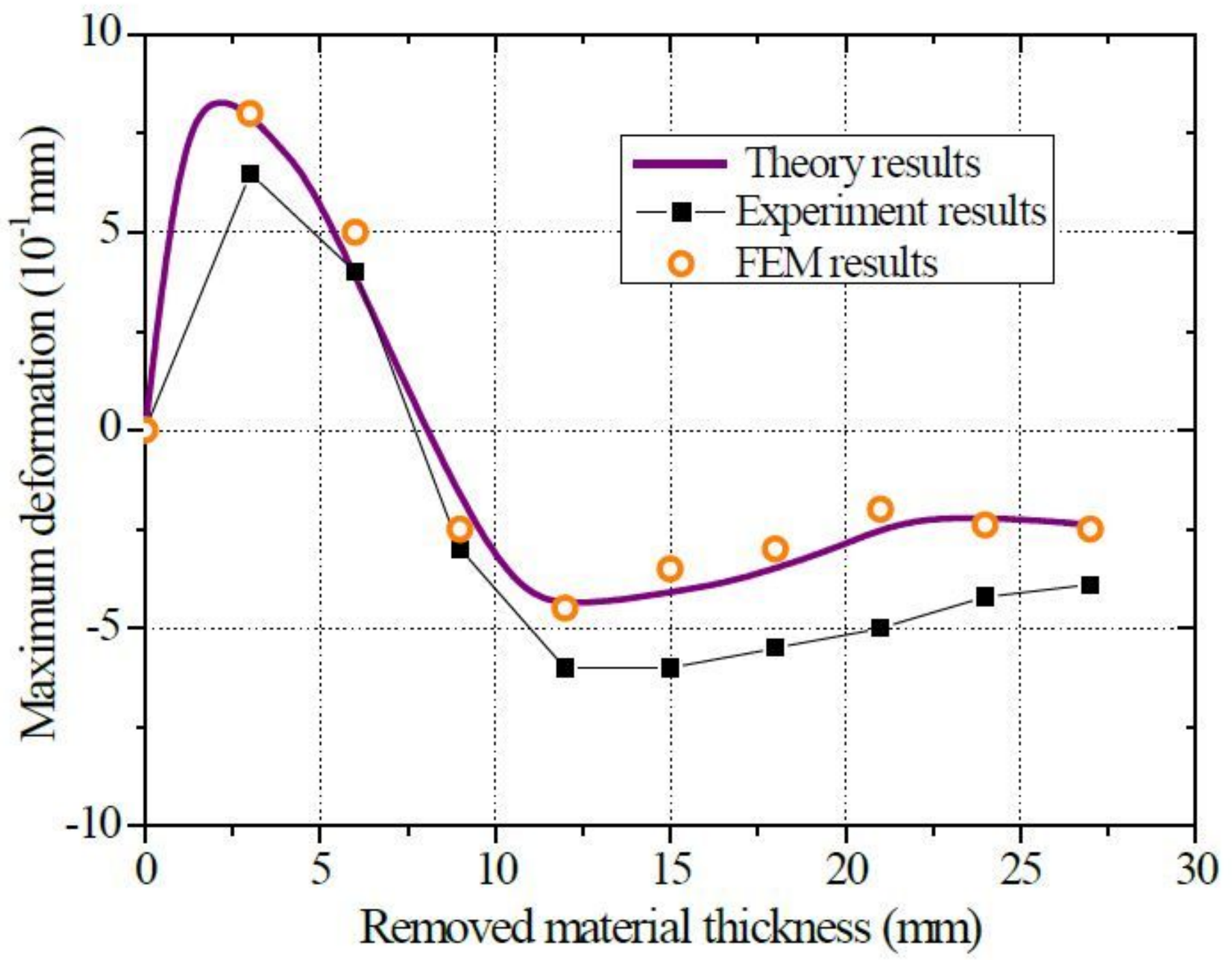

Figure 12

Maximum deformation evolution during material removed 


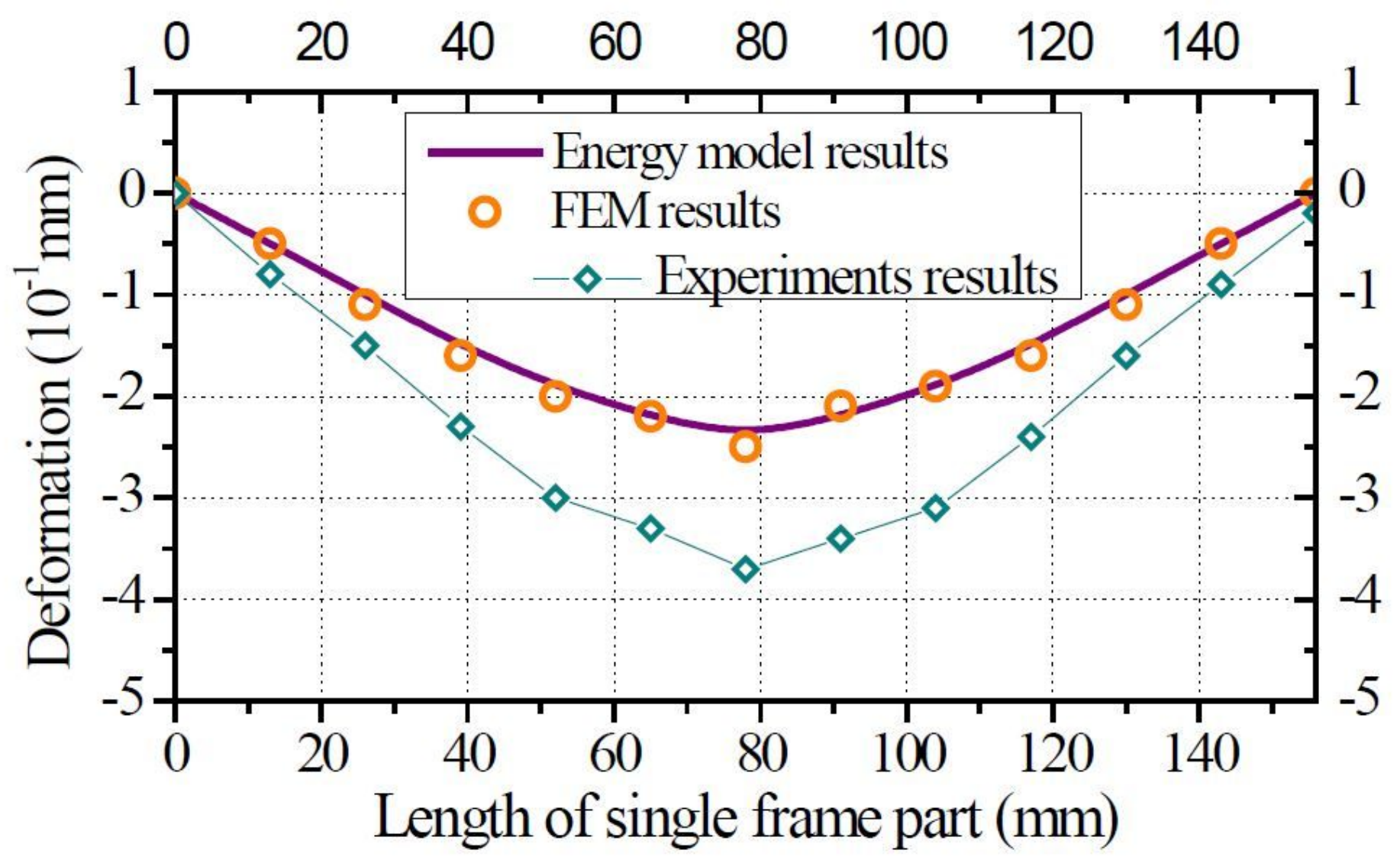

Figure 13

Deformation comparison between energy model, FEM and experiment results 